\title{
Effect of the Role of Family Function on the Resiliency of Women with Addicted Husband in Tehran
}

\author{
*Reza Shahmahmoudi \\ MA in Sociology \\ Email:shahmahmoudi.reza@gmail.com

\section{Dr. Mohammad Javad Zahedi Mazandarani} \\ Associate Professor at Payam Noor University of Tehran \\ Email: m_zahedi@pnu.ac.ir
}

Doi:10.5901/mjss.2015.v6n1s1p400

\begin{abstract}
Social helpers can play an important role in empowering vulnerable groups. One of these vulnerable groups is women with addicted husband that encounter with the crisis of addiction of their husband in life. Undoubtedly, one of the practices in the field of empowering them is enhancement of their resiliency. Recognition of effective factors on the resiliency can be helpful in direction of empowering them in next steps. The purpose of the current study was to investigate the effect of the role of family function on the resiliency of women with addicted husband. In viewpoint of data collection, the method of current research is descriptive research (non-experimental) from field study branch and in viewpoint of the relationship among research variables this study is a type of correlation. Statistical population of the current research was women with addicted husband in Tehran that 350 of them were selected based on Cochran's formula and were studied using a simple random method. In order to collect data and required information in this study, standard family assessment device (FAD) and Conner and Davidson's standard resiliency questionnaire (2003) were used. Data were tested using SPSS software and correlation and multivariable regression tests. The results showed that there is a significant positive correlation between family function and the resiliency of women with addicted husband $(r=+0.343, P<0.01)$, between problem solving and the resiliency of women with addicted husband $(r=+0.343, P<0.01)$, between communications function and the resiliency of women with addicted husband $(r=+0.624$, $P<0.01)$, between role and responsibility and the resiliency of women with addicted husband $(r=+0.414, P<0.01)$, between blended emotions and the resiliency of women with addicted husband $(r=+0.375, P<0.01)$, between behavioral control and the resiliency of women with addicted husband $(r=+0.675, P<0.01)$. Also, the results of multivariable regression showed that all of components of family function are as a predictor of the resiliency of women with addicted husband $(P<0.01)$. The results of this research can be helpful for social helpers, policymakers and programmers in order to programming in direction of empowering vulnerable groups such as women with addicted husband.
\end{abstract}

Keywords: Family, Family function, Resiliency, Women with addicted husband, Social helpers.

\section{Introduction}

The family is the first and the most fundamental entity that plays a basic role in formation of identity of a person. Human begins his/her life from the family and the basis of his/her identity is originated and his/her values and mental measures are established from/in there. These initial effects on behaviors, person's communications with others, and consistency with surrounding play a determinant role in future and generally in whole life (Vahedi et al., 2009). Attention to the family and attempt for solving problems of this fundamental organization can promise a valuable and high level society (Mousavi, Moradi and Mahdavi Hersini, 2005). Family function is as one of important indices guaranteeing life quality and metal health of family and its members and it can be a key factor in creating flexibility and decreasing the current and future dangers related to improper conditions (Silborn, Zubrick, De Maio, Shepherad, and Greeffin, 2006). The results of studies have shown that desirability, satisfaction, quality and optimal function of family are as effective factors on growth, flourishing and advancement of family members (Behboudi et al., 2009). And attainment to a health society depends on health family and health family depends on mental health of people and having suitable relation with each other. Proper family function can be helpful for its members to consist with undesirable conditions, unpleasant and stressful life. Disturbance in family function results in confusion, worry, and relational problems of its members and it can endanger the health of family members (Ghamari and Khoshnam, 2011). On the other hand, people usually feel helpless against 
undesirable conditions, dangers and adversities and in many times they try to bear dangers and unpleasant situations and earn unexpected results. Ability for implementation of this "common magic" is often interpreted as flexibility or "resiliency" in the field of social sciences. Resiliency in social sciences is assumed as "a reaction process against adversities" (Goldberg and Williams, 2003). Conner (2003) has defined resiliency as a method for measuring the person's ability against stressful factors and factors that threaten mental health of a person. Resilient people do not have selfbreaking behaviors. These people are calm emotionally and have ability to encounter with unpleasant conditions. Bona (2004) also knows the ways of achieving resiliency in having self-increasing, repressive confronting, moods, and positive feeling (Huang, 2007: 82). Resiliency is defined as a power or ability of returning to initial life and starting a new situation by decreasing nervous pressure or falsification of it and replacing exhilaration (Yazdani, 2012). Indeed, resiliency is the capacity of people for remaining healthy and withstanding against difficult and dangerous conditions that a person not only overcomes those conditions but also becomes stronger during it. So, resiliency means ability of being successful, living and self-growth in difficult and unpleasant situations (despite the risk factors). This process is not created spontaneously unless a person locates in an undesirable situation to attempt for relief from it or less vulnerability for discovery and utilization of protective factors (individual or environmental) inside or outside his/her own (Furnham and Chamoro-Premuzic, 2008). Conducted researches indicated that some of resilient people come back to normal level of function after encountering with difficult situations of life, while some others are promoted with respect to the past after encountering with failures, tragedies and difficulties. Since home is the first location in individuals' life, it must be such that the spirit feels calm and make a balance for its members. And the existence of a warm and maturing environment in family is a certain base for its members and guarantees the health of individuals (Nourouzi, 2003). Proper family function can be helpful for its members for consistency with unsuitable, unpleasant, and stressful life. Disturbance in family function results in confusion, worry, and relational problems of its members and it can endanger the health of family members (Ghamari and Khoshnam, 2011). Attention to the family and attempt for solving problems of this fundamental organization can promise a valuable and high level society (Mousavi, Moradi and Mahdavi Hersini, 2005). On the other hand, resiliency is a type of interaction with the danger factor means it has a growing essence that is originated from biology and initial life experiences and protective factors can be effective through different methods in various stages of growth (Conner and Davidson, 2003). Social helpers can have an important role in empowering vulnerable groups. One of these vulnerable groups is women with addicted husband that encounter with a crisis of addiction of husband in the life. Addiction of husbands has had irreparable results in women life and their family life (Nouri et al., 2010). And consequently in the field of addiction of husband, families have the least vulnerability that women of families have higher resiliency and undoubtedly one of the practices in the field of empowering them is enhancement of their resiliency and recognition of factors that play a role in their resiliency can be helpful in direction of empowering them in next steps. Therefore, this study aims to investigate the effect of the role of family function on resiliency of women with addicted husbands.

\section{Research Hypotheses}

1. Family function with resiliency of women with addicted husband has a significant positive relationship.

2. Problem solving in family with resiliency of women with addicted husband has a significant positive relationship.

3. Communications in family with resiliency of women with addicted husband has a significant positive relationship.

4. Role and responsibility in family with resiliency of women with addicted husband has a significant positive relationship.

5. Blended emotions in family with resiliency of women with addicted husband has a significant positive relationship.

6. Behavioral control in family with resiliency of women with addicted husband has a significant positive relationship.

7. Emotional response in family with resiliency of women with addicted husband has a significant positive relationship.

\section{Research Background}

In a descriptive study, Keshtkaran (2009) investigated the correlation titled "relation of family communicational patterns with resiliency in Shiraz university students" of 200 of first year bachelor students. Samples were selected using cluster 
sampling method. Applied tools include of adult resiliency scale (Friberg et al., 2003) and scale of revised family communicational patterns (Richi and Fitz Patrick, 1994) that Cronbach's alpha and factor analysis method were used to investigate the reliability of these tools and to investigate the validity, respectively. Both questionnaires showed a good reliability and validity. Regression analysis was used to study whether types of family communicational patterns have ability of predicting the resiliency. Variance analysis was applied to study the difference between types of family forms in aspect of resiliency. The results showed that dialogue dimension is a positive predictor of resiliency, but conformance dimension is a negative predictor of resiliency and there is a significant difference between various types of communicational patterns viz multiplicity-oriented and agreeing families and unconstraint and restricting family from aspect of resiliency. Alen Al-Krenawi (2013) in a study investigated the comparison of family function, matrimony satisfaction, life satisfaction, and self-esteem in women with bigamy husband and women with monogamy husband. The results of the research indicated that women with bigamy husband reported weaker family function, lower self-esteem, lower matrimony satisfaction, and lower satisfaction from life with respect to control groups. This means the presence of the other women in husband's life has had a deep effect on family function and has resulted in decrease in satisfaction from life, matrimony satisfaction, and self-esteem. Berge et al. (2012) showed that family function is related to weight status, eating, behaviors and physical activity of teenagers. Their research resulted showed that girl teenagers in a family with better function had lower mass body index and extra weight percent; they were less sedentary than others and consumed vegetables and fruits more than their peers; they spent more meal time with their family and paid more attention to eat breakfast. On the other hand, boy teenagers with better family function had more physical activity than their peers; they had less sedentary and served meal with their family; they paid more attention to breakfast than the others. Ha JY (2010) investigated the effect of family function, social support and self-esteem on appearance of stress in graduate students. His research results showed that family function, social support and self-esteem are as a predictor of the stress within graduate students such that the better family function, the more social support; they reported lower stress. Whatever students have lower self-esteem, they report more stress. This study emphasizes on the role of family function and social support in appearance of mental disorders.

\section{Theoretical Framework}

\subsection{Empowerment theory}

It is one of the most famous theories of social assistance; Enhancement of the authority and power for a person to select a resource, increasing of self-confidence and capacity in decision-making. Empowerment means the enhancement of the authority and power for a person to select a resource and applying ideas in decisions that affect his/her life. Empowerment leads to increase the self-confidence and capacity of people in decision making. Empowerment occurs in personal, social, and group levels. An issue that exists in empowerment is that the linking between a person and the society is necessary (Sam Aram, 2012). In this research, social helpers through better recognition of effective factors on resiliency of women with addicted husband can provide the practices in the field of their better consistency with current life conditions and empower them.

\subsection{Intervention in crisis theory}

This theory is one the most prominent theories in social helping. People encounter with various crises during their life that these crises result in imbalances in the society. The purpose of this theory is to decrease the damages and rebuild the society (Sam Aram, 2012). Women with addicted husband also encounter with the crisis of the addiction of their own husband and this crisis is effective on their health; social helpers through recognition of effective factors on resiliency of women with addicted husband can take a step in order to empower them.

\subsection{Social health theory}

This theory is also one of prominent theories in social helping. How a person communicates with others in the society and socialization are discussed in this theory (Sam Aram, 2012). Empowering women with addicted husband can result in amplification of their relationship with society can also be effective on children health and finally, society health. A combination of these three theories can be considered as a theoretical framework for current research. 


\section{Methodology}

This study is a descriptive research (non-experimental) from field study branch from aspect of data collection and it is a kind of correlation in view point of relation among research variables. Statistical population of this research is all women with addicted husband in Tehran that 350 of them were selected based on Cronbach formula and were studied using simple random method. In this research, standard family assessment device (FAD) and standard resiliency questionnaire were used in order to collect data and required information. Family assessment device (FAD) has 60 questions that have been developed by Epestein, Baldion, and Bishop in 1983 based on McMaster pattern. ZadehMohammadi and Malek Khosravi (2006) reported the reliability coefficient for whole questionnaire, microscales of problem solving, communications in family, behavioral control in family, and emotional response in family $0.71,0.722,0.70,0.71,0.736$, $0.66,0.71$, respectively. This questionnaire includes of 6 dimensions (function, problem solving, communications, roles, blended emotions, behavioral control, and emotional response) and total score of the questionnaire shows the family function.

The higher score in this questionnaire shows healthier function of family. All of answers are coded from 1 to 4 . Score of each question will be from 1 to 4. Questions of each dimension are added together indicating the family function in that dimension. Also, in this research data were entered in SPSS software after completion of questionnaire by 30 people from research samples; the reliability coefficient using Cronbach's alpha for whole, problem solving dimension, communications, role and responsibility, blended emotions, behavioral control, emotional response was obtained 081, $0.78,077,0.82,0.72,0.76$, and 0.80 , respectively showing acceptable reliability of research questionnaire. Resiliency questionnaire of Conner and Davidson (2003) includes 25 items and was provided by Conner and Davidson (2003) in order to measure ability against pressure and threat. This scale investigates various dimensions of resiliency including individual ability sense, strength against negative effects, positive acceptance of change, confidence on individual instinct, sense of social support and security, spiritual faith pragmatism approach to problem solving methods. For each item, five-option gradation spectrum (completely false to always true) was considered that was scored from 1 (completely false) to 5 (always true). This questionnaire was prepared by Conner and Davidson (2003) through reviewing research references in 1979-1991 in the field of resiliency. The questionnaire includes of 25 items that is scored in a Likert scale from completely false (score 0 ) to completely true (score 5). To determine validity of this scale, first, correlation of each item with total score was calculated and then factor analysis was applied. Calculations of correlation of each score with total score except item 3 showed coefficients from 41 to 64 . The items of the scale were analyzed based on main component method. Before extraction of factors based on matrix, correlation of items was calculated in KMO index and Bartlett sphericity test. KMO amount was 0.87 and both amounts in Bartlett test was 28.5556 indicating adequacy index of control groups for factor analyzing. To determine validity of the scale, Cronbach's alpha was used and validity coefficient was obtained 0.89 (Edward Karenli, 2005). Mohammadi (2005) normalized this questionnaire in Iran for the first time and reported a high validity of 0.80 for it. In the current research, Cronbach's alpha coefficient was calculated for all questions of the resiliency test in order to compute validity of resiliency test; Cronbach's alpha coefficient was obtained 0.847 showing a very good internal identification of resiliency test questions. And according to the research hypotheses, proper inferential statistics of each hypothesis such as correlation and regression analysis were used.

Table 2 - Descriptive indices of questionnaire scores of resiliency

\begin{tabular}{|c|c|c|c|}
\hline Variable & Number & Average & Standard Deviation \\
\hline Resiliency & 350 & 89.63 & 14.66 \\
\hline
\end{tabular}

The results show that average family function of women with addicted husband and the resiliency of addicted-husband women are 125.24 and 89.63 , respectively.

Table 3 - Correlation coefficient results for family function with resiliency

\begin{tabular}{|c|c|c|c|}
\hline Variables & Number & Correlation coefficient & Significance \\
\hline Family function-Resiliency & 350 & $+0.343^{\star \star}$ & 0.001 \\
\hline
\end{tabular}

** $\mathrm{P}<0.01 * \mathrm{P}<0.05$

The results from Table 3 show that there is a significant positive correlation between family function and resiliency of women with addicted husband in a level lower than $0.01(r=+0.343, P<0.01)$. Therefore, it can be concluded that with 
enhancement of family function scores, the resiliency scores of women with addicted husband increases.

Table 4 - Correlation coefficient results for components of family function with resiliency

\begin{tabular}{|l|c|c|c|}
\hline Variables & Number & Correlation coefficient & Significance \\
\hline Resolving of problem-Resiliency & 350 & $+0.343^{\star \star}$ & 0.001 \\
\hline Communications-Resiliency & 350 & $+0.624^{\star \star}$ & 0.001 \\
\hline Role and responsibility-Resiliency & 350 & $+0.414^{\star \star}$ & 0.001 \\
\hline Blended emotion-Resiliency & 350 & $+0.375^{\star \star}$ & 0.001 \\
\hline Behavior control-Resiliency & 350 & $+0.675^{\star \star}$ & 0.001 \\
\hline Emotional Response-Resiliency & 350 & $+0.721^{\star \star}$ & 0.001 \\
\hline
\end{tabular}

${ }^{*} \times \mathrm{P}<0.01 * \mathrm{P}<0.05$

The results from Table 4 show that there is a significant positive correlation between resolving of the problem and resiliency of women with addicted husband in a level lower than 0.01 ( $r=+0.343, P<0.01)$. Therefore, it can be concluded that with enhancement of scores of resolving problem of the family, the resiliency scores of women with addicted husband increases. There is a significant positive correlation $(r=+0.624, P<0.01)$ between communications and resiliency of women with addicted husband in a level lower than 0.01 . Therefore, it can be concluded that with enhancement of scores of family communications, the resiliency scores of women with addicted husband increases. There is a significant positive correlation $(r=+0.414, P<0.01)$ between role and responsibility and resiliency of women with addicted husband in a level lower than 0.01 . Therefore, it can be drawn that with enhancement of scores of role and responsibility of family, the resiliency scores of women with addicted husband increases. There is a significant positive correlation ( $r=+0.375$, $\mathrm{P}<0.01$ ) between blended emotions and resiliency of women with addicted husband in a level lower than 0.01 . Therefore, we can conclude that with enhancement of scores of blended emotions of family, the resiliency scores of women with addicted husband increases. There is a significant positive correlation $(r=+0.675, P<0.01)$ between behavior control and resiliency of women with addicted husband in a level lower than 0.01 . Therefore, it can be drawn that with enhancement of scores of behavior control of family, the resiliency scores of women with addicted husband increases. There is a significant positive correlation $(r=+0.721, P<0.01)$ between emotional response and resiliency of women with addicted husband in a level lower than 0.01 .

Therefore, it can be drawn that with enhancement of scores of emotional response of family, the resiliency scores of women with addicted husband increases.

Table 5 - Investigating the relation of organizational culture dimensions on knowledge sharing

\begin{tabular}{|l|c|c|c|c|c|}
\hline Resource & Summation of squares & Degree of freedom & Square of average & Statistic $F$ & $p$-value \\
\hline Regression model & 11635.565 & 9 & 1292.841 & 101311.099 & 0.001 \\
\hline Remaining & 2.310 & 181 & 0.013 & & \\
\hline Summation & 11637.874 & 190 & & & \\
\hline
\end{tabular}

According to Table 5 , it is observed that $p$-value is lower than 0.05 , so, the regression model of effect of family function on the resiliency of women with addicted husband is significant.

Table 6 - Investigating the effect of family function dimensions on the resiliency of addicted-husband women

\begin{tabular}{|l|c|c|c|c|c|}
\hline \multirow{2}{*}{} & \multicolumn{2}{|c|}{ Non-standard coefficients } & Standard coefficients & \multirow{2}{*}{ Statistic F } & \multirow{2}{*}{ p-value } \\
\cline { 2 - 3 } & $\mathrm{B}$ & Standard error & Beta & & \\
\hline Constant amount & 52.972 & 0.235 & - & 225.285 & 0.001 \\
\hline Resolving of problems & 0.916 & 0.020 & 0.348 & 46.058 & 0.001 \\
\hline Communications & 0.782 & 0.011 & 0.197 & 73.620 & 0.001 \\
\hline Role and responsibility & 11.340 & 0.041 & 2.092 & 277.217 & 0.001 \\
\hline Blended emotions & 3.781 & 0.037 & 0.687 & 102.134 & 0.001 \\
\hline Behavior control & 6.345 & 0.019 & 2.018 & 330.780 & 0.001 \\
\hline Emotional response & 1.692 & 0.034 & 0.342 & 49.494 & 0.001 \\
\hline
\end{tabular}

According to Table 6, it is observed that p-value of all of dimensions is lower than 0.05 and then, all of family function 
dimensions have a significant positive effect on resiliency of women with addicted husband and these components are as a predictor of resiliency of women with addicted husband.

\section{Discussion and Conclusion}

In this research, 350 of women with addicted husband in Tehran were studied. The results showed that there is a significant positive relationship between family function and its components (problem solving, communications, role and responsibility, blended emotions, behavioral control, and emotional response) with resiliency of women with addicted husband. In other words, with increasing family function and its components, resiliency of women increases. Previous researches have indicated that family function is effective on satisfaction from life and self-esteem and families with better function have reported better satisfaction from life than others whilst better family function results in increased selfesteem (Alen Al-Krenawi, 2013). The research results also showed that family function is effective on life style of people. People with better family function prefer to stay with their family more than others and even eat meal beside family (Berge et al., 2012). Also, researches have shown that better family function accompanies by better mental health of family members (Naghavi and Redzuan, 2012) and decreased depression (Wu, Sun, Zhang, and Ren, 2012). Ha JY (2010) in a study showed that family function is as one of predictors of appearance of stress within persons. About the mechanism of family function, researches have shown that family function can be a key factor in creating flexibility and decreasing current and future dangers related to unpleasant events and unsuitable conditions (Silborn et al., 2006). Some of experts believe that family function not only consists of factors such as welfare facilities of family and education of parents but also includes of ethical growth of family, way to communicate among members, suitability family rules, division of roles, encountering way with a problem by family members, expression of affections, preparation of emotional requirements, and so on (Epstein, Baldwin, Bishop, 1983; quoted by Rafiee, Tavan, and Jahani, 2011). In some studies, blended emotions and behavioral control have been known as predictors of disciplinary desirable behaviors in persons (Yoseliani, Habibi and Soleimani, 2012). According to the findings of this research, social helpers can take a step in the fields of empowering these women with family intervention and amplification of family function through referring these women for participating in training and consulting programs. In this direction, Ghamari and Khoshnam (2011) also reported that in order to promote the life quality of people we can improve their family function through training and consulting programs. Also, studies have shown that there is a significant positive correlation between better function of the family and selfefficiency (Abbasi and Hojjati, 2009). On the other hand, based on the results of Broux (1994), Werner (1997), Wright and Masten (1997) research, emotional support of family members from each other facilitates the confronting with life pressures or in other words the resiliency of people against the problems increases (Karami, Sharifi and Boshildeh, 2009). Form the results of the current study, it can be concluded that family function has a deep effect on the resiliency of women with addicted husband and social helpers in the direction of empowering addicted-husband women can carry out some interventions in the field of amplification of family function and its components and these interventions can be in form of training programs, consulting meetings and/or group consultations. Research findings can be helpful for policy makers and programmers in direction of empowering this vulnerable group.

\section{References}

Abbasi M, Hojjati M, (2009), Investigating the relation between family function and self-efficiency of boy students in Allameh Tabatabaei university, Tehran: first congress on family, student, university.

Alean Al-Krenawi. (2013). A study of psychological symptoms, family function, marital and life satisfactions of polygamous and monogamous women: The Palestinian case. Int J Soc Psychiatry. 58(1): 79-86. doi: 10.1177/0020764010387063. Epub 2010 Nov 18.

Behboudi M, Hashemian K, Sharifi H.P, Navvabinejad Sh.H, (2009), Prediction of family function based on characteristics of couples, Thought and Behavior, 3(11), pp. 55-66.

Berge J. M., Wall, M., Larson, N., Loth, Katie A. Neumark-Sztainer, D. (2012). Family Functioning: Associations With Weight Status, Eating Behaviors, and Physical Activity in Adolescents. Journal of Adolescent Health. Volume 52, Issue 3, pp. 351-357.

Conner KM, Davidson JRT. (2003). Development of a new resilience scale: The Conner-Davidson resilience Scale (CD-RISC). Depression and Anxiety; 18: 7682.

Edward, Karen-leigh (2005). The phenom enon for resilience in Crisis care mental health clinicians, international journal of mental health nursing: 14(2): 142-148.

Furnham, A \& Chamoro-Premuzic, T. (2008). Personality and intelligence as predictors of statistics examination grades. Personality and Individual Differences; 37: 943-955

Ghamari, M, Khoshnam M, (2011), Investigating the relation of main family function and life quality among students, scientific-research quarterly journal of family research, 7(2), pp. 343-354. 
Goldberg D. P \& Williams P. (2003). The user guide to General Health Questionnaire. Windsor: Nelson.

Ha JY. (2010). Impact of Self-esteem, Family Function and Social Support on Stress in Undergraduate Students. J Korean Acad Fundam Nurs. 2010 May; 17(2): 259-266.

Korean available at: http://www.koreamed.org/SearchBasic.php?RID=0091JKAFN/2010.17.2.259\&DT=1

Huang, C. (2007). Hardiness and stress: A critical review. Maternal Child Nursing Journal; 2(3): 82-89.

Karami J, Sharifi Kh, Boshlideh K, (2009), Investigating the relation of family function with psychological tenacity in high school students in Kordestan, psychological consequences journal (educative and psychological sciences), Shahid Chamran university of Ahvaz, 4(2), pp. 167-188.

Keshtkaran T, (2009), The relation of family communicational patterns with resiliency in students of Shiraz university, Knowledge and Research in applied psychology, 39, pp. 69-88.

Mohammadi M, (2005), Investigating the effective factors on resiliency in people exposure to drug abuse, Ph.D thesis in clinical psychology. Tehran. Welfare and Rehabilitation science.

Mousavi R, Moradi A, Mahdavi Hersini S, (2005), Investigating the effect of structural family therapy on improvement of family function and amplification of matrimony satisfaction in families with separation disorder, Journal of family research, 1(4), pp. 321-335.

Naghavi F., Redzuan M., (2012). Relationships between Family Functioning, Alexithymia and Emotional Intelligence among Early Adolescents in Tehran-Iran. Life Science Journal, 9(1). http://www.lifesciencesite.com

Norouzi V, (2003), Effect of behavioral styles of family on psychological status of students and on their attitude to human relations in school, Journal of educational innovations, 2(6), pp. 31-54.

Nouri R, Rafiei H, Akbarian M, Narenjiha H, (2010), Comparison of characteristics, emotional senses and satisfaction expression from husband in women with addicted husband and women with healthy husband, Journal of investigation of Iranian social issues, $1(4)$, pp. 55-71.

Rafiee M, Tavan B, Jahani F, (2011), Investigating the relation of family function and religious attitude of line and staff personnel of Arak medical science university in 1390, Medicine and Refinements, 20(3 and 4), pp. 33-44.

Sam Aram A, (2012), Social helping theories and localization of them, programming of welfare and social development, magazine of first social welfare congress in Iran, pp. 1-40.

Silborn, S., Zubrick, S., De Maio, J., Shepherad, C., \& Greeffin, J. (2006). The western Australian Aboriginal child health survey: Strengthening the capacity of Aboriginal children, families and communities. Perthicurtin University of technology and telethon institute for child health research [On-line]. Available: www.childhealthre-search.com.au/waachs/publications.

Soleimaninia L, (2005), Prediction of dangerous behaviors of teenagers based on positive and negative dimensions of mental health. M.Sc. of thesis in clinical psychology, Tehran. Welfare and Rehabilitation science.

Vahedi Sh, Lotfinia H, Yousefi Shahir N, (2009), Relation of parenting methods and emotional atmosphere of family with children creativity in pre-school centers in Tabriz, woman and family studies, 1(3), pp. 107-121.

Wu JH, Sun CL, Zhang SM, Ren XH. (2012). [Relationship between depression and family function in old patients with coronary heart disease]. Sichuan Da Xue Xue Bao Yi Xue Ban. 43(3):401-3. available at : http://www.ncbi.nlm.nih.gov/pubmed/22812246

Yosliani Gh, Habibi M, Soleimani A, (2012), The relation of disciplinary behavior with family function, control resource and self-esteem of students, School psychology journal, 1(2), pp. 114-134.

ZadehMohammadi A, MalekKhosravi Gh, (2006), Primary investigation of psychometric properties and validation of family assessment device scale, Quarterly journal of family research, 5, pp. 69-89. 